\title{
Suitability of Tamarind and Some Selected Crop Seeds for the Survival and Development of Sitophilus Linearis (Herbst) (Coleoptera: Cucurlionidae)
}

\author{
Adebayo R.A. (Corresponding author) \\ Department of Crop, Soil and Pest Management \\ Federal University of Technology Akure, Ondo State, Nigeria \\ $\&$ \\ Insect Science Programme (ARPPIS), University of Ghana, Legon \\ Tel: 234-703-866-1128Ｅ-mail: abiodun1400@yahoo.com \\ J.N. Ayertey \\ Insect Science Programme (ARPPIS), University of Ghana, Legon \\ $\&$ \\ Department of Crop Science, College of Agriculture and Consumer Sciences \\ University of Ghana, Legon \\ M.A. Cobblah \\ Insect Science Programme (ARPPIS), University of Ghana, Legon \\ $\&$ \\ Department of Zoology, Faculty of Science, University of Ghana, Legon
}

Received: June 2, 2010 Accepted: June 17, 2010 doi:10.5539/ijb.v3n3p83

\begin{abstract}
Sitophilus oryzae (L.), Sitophilus zeamais (Mots.) and Sitophilus granarius (L.) are major pests of stored grain, especially on cereals. Sitophilus linearis (Herbst) a congeneric of the afore-listed species was obtained from seeds of a wild plant, Tamarindus indica L. The development of S. linearis on some selected crop seeds as well as tamarind seeds was investigated in the laboratory at $25.3-30.3{ }^{\circ} \mathrm{C}$ and $75.0 \% \pm 5.0 \mathrm{RH}$. One hundred grammes each of heat sterilized maize, rice, sorghum, millet, cowpea and tamarind seeds were infested with 100 unsexed adults of S. linearis and observed to determine the suitability of the different substrates for the development of the weevil. Sitophilus linearis bred and multiplied on the tamarind seeds but not on the selected crop seeds in the laboratory. Mean developmental period on the tamarind seeds was 32 days. The highest number (51) of adults that emerged on the first day of emergence was from cultures set up with one-week old adult insects. The highest mean weight $(3.9 \mathrm{mg})$ was also recorded on the cultures set up with one-week old insects. However, both mean number of emerged adults and mean adult weight were not significantly different $(\mathrm{P}>0.05)$. A significant difference was recorded in the mean percentage survival period of $S$. linearis on the different substrates $(\mathrm{P}<0.05)$ with the longest survival recorded on tamarind seeds. It can therefore be concluded that Sitophilus linearis, though a member of the family of grain weevils, could not reproduce on the cereal substrates or the cowpea seeds presented to it in the laboratory. If further studies confirm these findings, then Sitophilus linearis may pose no threat to cereal production due to its inability to survive and reproduce on them.
\end{abstract}

Keywords: Curculionidae, Dryophthorinae, Congenerics, Infestation, Viability, Cereal, Substrate

\section{Introduction}

The Tamarind weevil, Sitophilus linearis (Herbst) belongs to the family Curculionidae, Subfamily 
Dryophthorinae, Genus Sitophilus. Other species in the same genus include Sitophilus oryzae (L.), Sitophilus zeamais (Mots.) and Sitophilus granarius (L.) which are stored grain pests. The three species alone consume \$35 billion dollars worth of the world's grain annually and during World War I, it is reported that infestations of grain stores in Australia were so severe that at one site alone, one billion weevils (i.e., over one ton) were swept up daily and destroyed (Zimmerman, 1993). The tamarind pod-borer was described in 1797 by Herbst under the name of Rhynchophorus linearis, in 1834 by Christy under the name Calandra tamarindi, and finally in 1837 by Dejean under the specific name frugilega. In 1892 Casey noted the occurrence of Sitophilus linearis in North America, but in 1895 Chittenden stated that $S$. linearis should not be inserted in the faunal list until it could be ascertained that the species actually bred in some plant within the faunal limits.

Sitophilus linearis is similar in general form to Sitophilus oryzae. However, it is more robust and the rostrum is shorter. The prothorax has fine punctures that are separated by a distance at least as great as the diameter of a puncture, and the surface between punctures is smooth and shining (Haines, 1991). The genus Sitophilus and its species, though are almost indistinguishable from each other externally may be identified using the keys of Gorham (1987) or Haines (1991). Hill (1993) reported adult body size of between $2.5 \mathrm{~mm}$ and $4 \mathrm{~mm}$ for Sitophilus oryzae and S. zeamais, but S. linearis could be relatively larger. Total developmental periods from egg to adult varies from 30-35days under optimal conditions but may be prolonged by sub-optimal conditions of temperature and relative humidity (Haines, 1991). A developmental period of 25-30 days has been reported at average temperatures of $26.3{ }^{\circ} \mathrm{C}$ and $27.4{ }^{\circ} \mathrm{C}$ for the month of June and July respectively, in New Orleans, America (Cotton, 1920). Like other Sitophilus species which are multivoltine, S. linearis produces many generations in one year and its longevity may vary from a few months to years (Cotton, 1920; NRI, 1996). Unlike the grain weevils where the eggs hatch after about 8 days into legless, $4 \mathrm{~mm}$ long larvae (NRI, 1996), the eggs of $S$. linearis hatch at 3 days after being laid into larvae. The fourth instar larva lives within the chamber and moults into a prepupa (Cotton, 1920).This is followed immediately by a pupal stage which lasts for seven days before reaching the adult stage The adult does not immediately leave the seed but remains within to harden and feed for a few days (about 3-4 days) (Cotton, 1920). These weevils are among the most serious cosmopolitan pests of stored cereal grains in the tropic and sub-tropic regions (Throne, 1994). The developmental activities of the weevils often lead to severe powdering and tainting of the grains with excrement and the infested grains are often rendered susceptible to caking and mould infection thereby reducing their market value (Lale and Ofuya, 2001). In stored maize, heavy infestation of this pest may cause weight losses of as much as $30-40 \%$, although losses are commonly 4-5\% (Lale and Ofuya, 2001).

Though considerable works on the biology and development of the common species of Sitophilus have been carried out on food crops, little information is available on S. linearis in this regard. This study sought to investigate and compare the development of S. linearis on some crop seeds as well as the tamarind seed under laboratory conditions, so as to determine the extent to which $S$. linearis could pose a threat to food grains in storage.

\section{Materials and Methods}

\subsection{Study area}

While investigating the possible role that seeds of wild plants could play as alternate hosts of insect pests of stored food grains, seeds of tamarind (Tamarindus indica) plants were collected from the Botanical Garden of the University of Ghana, Legon. Seeds of some selected crop plants: maize, sorghum, millet, rice and cowpeas used for comparison in the study were obtained from the Madina market, near Accra. All seeds were initially kept under cold storage at a temperature of $10^{\circ} \mathrm{C}$ ahead of the laboratory studies which were carried out at the Entomology Laboratory, Crop Science Department, University of Ghana, Legon. Ambient laboratory conditions of 25.3-30.3 ${ }^{\circ} \mathrm{C}$ and $26.7-75.0 \%$ R.H. were used for the experiments.

\subsection{Experimental Design and Set Up}

The experimental design used for the developmental studies on S. linearis was a Randomized Complete Block Design (RCBD), because adult insects of different age groups were used. Completely Randomized Design (CRD) was used for the survival (longevity) study. All the treatments were replicated four times, randomly arranged and held in trays with its supports immersed in industrial oil to prevent infestation by other insects.

\subsection{Culturing of Sitophilus linearis on the seeds of Tamarind}

To obtain a pure culture of $S$. linearis, about $1000 \mathrm{~g}$ of the seeds were drawn from the lot kept in the cold store and sterilized in a Gallenkamp Oven for 3 hours at a temperature of $60^{\circ} \mathrm{C}$ to kill off insects that may have survived the freezing temperatures (Allotey and Azalekor, 2000). One litre bottle jars were also washed and 
sterilized for 3 hours in an oven at a temperature of $60^{\circ} \mathrm{C}$ to kill any available insects and other microorganisms. The seeds were allowed to cool and $250 \mathrm{~g}$ samples weighed into four culture jars, after which 100 unsexed adults of $S$. linearis obtained from seeds collected from the field were introduced into each jar with the aid of an aspirator. The jars were then covered tightly with a fine mesh to prevent infestation of the samples by other insects whilst allowing ventilation. The jars were placed on the shelf in the laboratory to allow oviposition by females. After 14 days of oviposition, the adult insects were sieved out with (6-mesh/inch, John Laing International Ltd. U.K.) sieve. The cultures were then returned to the shelf in the laboratory until adult emergence. Adults emerging from these cultures were used for the experiments described here. Cultures were replicated four times and regular re-culturing was carried out at intervals to allow adequate supply of experimental insects throughout the study.

\subsection{Development of Sitophilus linearis on crop seeds and tamarind}

Five different crop seeds including Maize (Zea mays L.), Millet (Pennisetum glaucum L.), Sorghum (Sorghum bicolor L.), Rice (Oryza sativa L.) and Cowpea (Vigna unguiculata L) were selected and used for this test. The seeds of tamarind on which the Sitophilus linearis were collected were also used as a substrate and replicated four times. Prior to the seed storage, one litre bottle jars were washed and heat sterilized as described above. Other seeds were also heat sterilized as described already to maintain a pure culture of insects. Prior to infestation, the moisture content of the tamarind, maize, millet, rice, sorghum and cowpea substrates were determined using a Digital Grain moisture meter (Protimeter PLC, England). The moisture contents of the substrates were: Tamarind seeds $(16.0 \%)$, maize $(14.1 \%)$, sorghum $(13.0 \%)$, millet $(14.0 \%)$, rice $(13.5 \%)$ and cowpea (14.50\%). About $100 \mathrm{~g}$ of each seed sample was weighed separately into the jars after which 100 unsexed adult $S$. linearis of different age groups (1-week, 2-weeks and 3-weeks old) were introduced into each jar with the aid of an aspirator. The jars were then covered tightly with a fine mesh to allow ventilation but prevent contamination of the cultures. Each crop seed type was replicated four times and arranged randomly on plastic trays as described above. The introduced insects were sieved out after a week of oviposition on the seeds using the 6-mesh/inch sieve. The use of insects of different age groups was to ensure inclusion of peak oviposition of the insects. Monitoring of the set-up was carried out until the emergence of the F1 generation. On emergence the number of adult insects were counted and recorded daily until no more insects were observed. The weight of adults emerging from each substrate was also taken using a sensitive Mettler Balance and recorded.

\subsection{Survival of Sitophilus linearis on seeds of Tamarind, Maize and Sorghum}

Ability of insects to survive and grow on a host is determined by its ability to establish and breed on that particular host. The suitability of a host crop for an insect can be deduced from the numbers of the insect that can be supported by the particular host. While some plants species are best for survival, others may also be suited for egg production. A test was therefore conducted to determine the survival (longevity) of $S$. linearis on seeds of tamarind, maize and sorghum. Prior to infestation, the moisture content of the tamarind, maize and sorghum substrates were determined as described earlier. One hundred grammes of each substrate were weighed separately into each of four glass jars and replicated four times. One hundred, unsexed, 2 weeks old adults $S$. linearis were introduced into each glass jar. Live insects were counted monthly and put back into the jars while dead insects were removed. This continued for four months (December, 2006 to March, 2007).

\subsection{Statistical Analysis}

Data generated from the study were analyzed using Genstat software version 5 Release 3.2 (Lawes Agricultural Trust, 1995). Data collected on the developmental study were transformed using square root of $(x+1)$, and data on survival (longevity) were transformed using arcsine of $\sin ^{-1}(\sqrt{ } x+1)$ to meet analysis of variance assumptions of normality and homogeneity of variances and subjected to analysis of variance at $95 \%$ level of significance. Means were separated using Least Significant Difference (LSD). Graphs were drawn using Microsoft excel and tables were used to summarize the results. Since no adult weevils emerged from maize, rice, millet, sorghum and cowpea, data on the developmental period and mean weight of adults on these crops were not included in the statistical analysis.

\section{Results}

\subsection{Development of S. linearis on different substrates}

The results of the developmental study revealed the inability of Sitophilus linearis to develop and breed on the various crop seeds under the laboratory conditions of $25.3-30.3{ }^{\circ} \mathrm{C}$ and $26.7-75.0 \% \mathrm{RH}$. However, seeds of tamarind on which the insects were reared were susceptible to attack and supported the development and breeding of the insects in the laboratory. Sitophilus linearis emerged from all the different age groups used 
(1-week, 2-weeks and 3-weeks old adults) in 33, 31 and 31 days respectively with a mean developmental period of 32 days, based on the middle point of oviposition to time of $50 \%$ emergence (Table 1). Of the three age groups used to set up the cultures, 1- week old adults produced the highest number of offspring though the differences were not significant (Table 2). The highest number of emerged insects was recorded on the first day of emergence, with a mean of fifty-one (51) adult insects from the jars seeded with one-week old insects, whilst the highest number of insects was recorded on the second day of emergence, with a mean of twenty seven (27) adult insects from the jars infested with two-weeks old insects. Adult insects also emerged from the set up with 3- week old insects and peak emergence was obtained on the seventh day with a mean of fifteen (15) adult insects. In all the cultures observed the number of adults that emerged decreased with time (Fig.1).

Statistical analyses revealed a non significant difference in the mean number of insects that emerged from cultures started with adults of different age groups $(\mathrm{P}>0.05$. The heaviest adult insect (weighing $3.9 \mathrm{mg}$ ) was obtained from the culture seeded with 1-week old adults followed by an insect of $3.8 \mathrm{mg}$ obtained from a culture set up with 2- weeks old adults (Figure 2).

\subsection{Survival of S. linearis on different substrates}

The results of the study of adult survival on different substrates over a 4-month period revealed that Sitophilus linearis survived longer on the tamarind seeds than on maize or sorghum seeds. The highest percentage survival $(93.75 \%)$ was on tamarind in the first month of the study (i.e. December). The lowest percentage survival $(26.76 \%)$ was recorded on maize in the month of February while sorghum and maize recorded $2.5 \%$ and $5.63 \%$ respectively during the month of March (Table 3). Tamarind seeds recorded the highest percentage (89.06\%) insect survival over the period of the study. Based on both substrate and period (months) the differences observed were significant $(\mathrm{P}>0.05)$ (see Table 3 ).

\section{Discussion}

\subsection{Developmental period of Sitophilus linearis}

The mean developmental period recorded for all the Sitophilus linearis adults that developed from cultures set up from all the age groups used was 32 days. This observed developmental period is within the range that has been reported by several authors. For example, Haines (1991) reported a total developmental period of 30-35days (from egg to adult) for $S$. linearis under optimal conditions but noted that it may be prolonged by sub-optimal conditions of temperature and relative humidity. A developmental period of 25-30 days has also been reported for S. linearis at average temperatures of $26.3^{\circ} \mathrm{C}$ and $27.4{ }^{\circ} \mathrm{C}$ for the months of June and July respectively by Cotton (1920). Similarly, Kossou et al. (1993) and Vowotor et al. (1994) found that development of S. zeamais, a close relative, was 31.5- 52.0 days from egg hatch to adult emergence at $25^{\circ} \mathrm{C}$ and $70-75 \%$ R.H. Differences in the reported developmental periods could be due to variations in the temperature, relative humidity and other prevailing experimental conditions, physical properties of the substrates and the species of insects under investigation.

The inability of S. linearis to develop on the cereal grains might be due to the absence of symbiotic bacteria in its gut as reported by Charles et al (1995). Delobel and Grenier (1993) have also revealed the inability of this species to be raised on grains, unlike its congeners which have been studied. Thus this study has showed that $S$. linearis will pose no threat to the production of cereal crops but awareness of its presence was further created. This may proffer a basis for further investigations into its biology.

\subsection{Weight and number of adult insects that emerged from the seeds of Tamarind}

A relatively high weight $(3.9 \mathrm{mg})$ was recorded for $S$. linearis in this study. This would confirm the findings of Haines (1991) who stated that S. linearis is larger than the other grain weevils. However most of the results obtained in this study (mean weights of $3.2 \mathrm{mg}$ and $3.3 \mathrm{mg}$ ) are similar to those weights that have been recorded for other grain weevils. These results are also similar to those observed by other authors. Adams (1976) reported a mean weight of $3.1 \mathrm{mg}$ for $S$. zeamais adults developing on maize, with moisture content of $13.5 \%$ at $27^{\circ} \mathrm{C}$ and $70 \%$ r.h. Vowotor (1992) working with S. zeamais also recorded adult weights of $3.07-3.4 \mathrm{mg}$ from different varieties of maize and $3.10-3.26 \mathrm{mg}$ for unshelled and shelled kernels in different storage forms in a laboratory at $25 \pm 2^{\circ} \mathrm{C}$ and $70 \pm 2 \%$ r.h. Mean weights of 3.16 and $3.05 \mathrm{mg}$ have also been reported for female and male weevils developing in the laboratory at $30^{\circ} \mathrm{C}$ and $70 \%$ r.h. (Danho et al., 2002). The heavier weight recorded for $S$. linearis here may be due to the substrate on which it was reared. Tamarind seeds may have provided readily available nutrients which are not present in the cereal grains on which its congeners are mostly reared. Other factors may also include the prevailing conditions. The highest adult emergences recoded for jars seeded with one week old insects suggested that maximum oviposition in S. linearis occurred when adults are 1-week old. 


\subsection{Survival of Sitophilus linearis on the test substrates}

The higher longevity of Sitophilus linearis on tamarind seeds confirms earlier observations by other researchers. Like other Sitophilus species which are multivoltine insect pests (NRI, 1996), S. linearis produces many generations in one year and the longevity of the weevil is from a few months to years (Cotton, 1920). Longstaff, (1981) and Lale (2002) have also reiterated the ability of the adult grain weevils to live up to one year. The inability to survive appreciably on maize and sorghum could be as result of symbiosis that has apparently been lost in Sitophilus linearis, which could have made it switch to eating legumes (Charles et al., 1995). It was clear from this study that weevils have the ability to live longer when the desired substrates and favourable experimental conditions are presented.

\section{Conclusion and Recommendation}

Sitophilus linearis, was able to survive, breed and multiply continuously on stored tamarind seeds in the laboratory. However, it could not develop on all the cereals and cowpea seeds presented to it in the laboratory. Previous studies have also revealed that $S$. linearis has lost the symbiotic bacteria that previously inhabited its gut, hence are unable to feed on cereal grains and consequently live for short periods on cereals grains. Based on these findings, it could be concluded that though S. linearis belongs to the same genus with other grain weevils, it poses no threat to stored products, especially cereal grains, as its congeners does. Results obtained from the developmental studies also show that maximum oviposition in Sitophilus linearis can be obtained by using one week (7 days) old adult insects and can therefore form the basis for raising laboratory cultures. It is therefore recommended that further studies be carried out on the biology of the Sitophilus linearis (Herbst) and other non-cereal stored products should be screened for attack by S. linearis while stored tamarind seeds should be evaluated further for its damage by S. linearis especially in areas where tamarind is of economic importance.

\section{Acknowledgement}

The authors acknowledge the German Academic Exchange Service (DAAD) for funding this work.

\section{References}

Adams, J.D. (1976). Weight loss caused by development of S. zeamais Motsch. in maize. J. stored Prod. Res., 12: 269-272.

Allotey, J. and Azalekor, W. (2000). Some aspects of the biology and control using botanicals of the rice moth, Corcyra cephalonica (Stainton), on some pulses. J. stored Prod. Res., 36 (3):235-243.

Casey, T. L (1892). Coleopterological notice IV. In Ann N.Y. Acad. Sci., V. 6, pp 359-717.

Charles, H., H. Ishikawa, and P. Nardon. (1995). Presence of a protein specific of endocytobiosis (symbionin) in the weevil Sitophilus. C. Royal Academy of Sciences, Paris, Life Sciences, 318: 35-41.

Chittenden, F. H. (1895). On the distribution of certain imported beetles. In Insect Life v. 7 num. 4, pp 326-332.

Cotton, R.T. (1920). Tamarind pod-borer, Sitophilus linearis (Herbst). Stored-Product Insect Investigations, Bureau of Entomology, United States Department of Agriculture, pp 439-446.

Danho, M., Gaspar, C. and Haubruge, E. (2002). The impact of grain quantity on the biology of Sitophilus zeamais Motschulsky (Coleoptera: Curculionidae) oviposition, distribution of egg, adult emergence, body weight and sex ratio. J. stored Prod. Res., 38:259-266.

Delobel, B. and Grenier, A.M. (1993). Effect of non-cereal food on cereal weevil and pod weevil (Coleoptera: Curculionidae). J. stored Prod. Res., 29 (1): 7 - 4.

Gorham, J.R. (1987). Insect and Mite pests in food: An illustrated key (Vols I and II). U.S. Dept. of Agriculture, Agriculture Handbook, No 655.USA.

Haines, C.P. (1991). Insects and Arachnids of tropical stored products: their biology and identification ( $2^{\text {nd }}$ eds.). National Resource Institute, Central Avenue, Chatham Maritime, Kent, U.K. 264pp.

Hills, D. S. (1993). Agricultural insect pests of the tropics and their control published by Manas Saikal Foundation Books, New Delhi, 746pp.

Kossou, D.K., Bosque-Perez, N.A and Mareck, J.H. (1993). Effects of shelling maize cobs on the oviposition and development of the maize weevil. IITA Res., 6:7-10.

Lale, N.E.S. and Ofuya, T. I. (2001). Pests of Stored Cereals and Pulses in Nigeria. Biology, Ecology and Control. Dave Collins Publication, Nigeria. 177pp

Lale, N.E.S. (2002). Stored Product Entomology and Acarology in Tropical Africa. Mole Publication, Nigeria. 
204pp.

Lawes Agricultural Trust. (1995).Genstat Software Version 5 Release 3.2 for Windows NT (Software for Statistical Analysis), Rothamstead Agricultural Station.

Locatelli, D.P. and Limonta, L. (1998). Development of Ephestia kuehniella (Zeller), Plodia interpunctella (Hubner) and Cocyra cephalonica (Stainton) (Lepidoptera: Pyralidae) on kernels and wholemeal flour of Fagopyrum esculentum (Moench) and Triticum aestivum L. J. Stored Prod. Res., 34 (4):269-276.

Longstaff, B.C. (1995). Biology of the grain pest species of the genus Sitophilus (Coleoptera: Curculionidae): A critical review. Protection Ecology, 2:83-130.

NRI (1996). Insects Pest of Nigerian Crops, Identification, Biology and Control. Nigerian Federal Ministry of Agriculture and Natural Resources and the Overseas Development administration of the British Government. Chatham, U.K. 253pp.

Throne, J. E. (1994). Life history of immature maize weevils (Coleoptera: Curculionidae) on corn stored at constant temperatures and relative humidities in the laboratory. J. Environmental Entomology, 23 145-147.

Vowotor, K.A. (1992). Effect of maize variety and storage on oviposition and development of maize weevil Sitophilus zeamais Motsch. (Coleoptera: Curculionidae) M.Phil.Thesis University of Ghana, Legon. 157pp.

Vowotor, K.A., Bosque-Perez, N.A and Ayertey, J.N. (1994). Effect of maize variety and storage form on oviposition and development of maize weevil Sitophilus zeamais, Motschulsky. (Coleoptera: Curculionidae). Stored Product Protection Proceedings of the Sixth international Working conference in Australia (Vol.1) CAB International, UK.pp.595-598.

Zimmerman, E. C. (1993). Australian Weevils. Volume III. CSIRO, Melbourne, 854pp.

Table 1. Mean Developmental period of Sitophilus linearis (Herbst) on seeds of Tamarind separately infested with 1, 2 or 3-week old adults for seven days

\begin{tabular}{|l|l|l|l|}
\hline Age of adult insects (weeks) & 1 & 2 & 3 \\
\hline Developmental period (days) & 33 & 31 & 31 \\
\hline
\end{tabular}

Table 2. Mean number and weight of adult Sitophilus linearis that emerged from cultures started with different age groups of adults

\begin{tabular}{|l|l|l|}
\hline Age of the insects (week) & Mean number of emergence* & Mean weight (mg)* \\
\hline 1 & $11.1 \pm 3.4^{\mathrm{a}}$ & $32 \pm 1.6^{\mathrm{a}}$ \\
\hline 2 & $9.2 \pm 1.8^{\mathrm{a}}$ & $33 \pm 1.0^{\mathrm{a}}$ \\
\hline 3 & $7.0 \pm 1.3^{\mathrm{a}}$ & $33 \pm 1.4^{\mathrm{a}}$ \\
\hline LSD (5\%) & 6.6 & 3.9 \\
\hline
\end{tabular}

LSD is the Least Significant Difference

S.E is the Standard Errors of Differences of means

* Means of untransformed data

Means bearing the same letter (superscript) in the same column are not significantly different at the 5\% probability Level

Table 3. Mean \% number of the adult Sitophilus linearis that survived on maize, sorghum and tamarind seeds over a period of four months

\begin{tabular}{|l|l|l|l|l|l|}
\hline Substrates & $\begin{array}{l}\text { December } \\
\pm \text { S.E }\end{array}$ & $\begin{array}{l}\text { January } \\
\pm \text { S.E }\end{array}$ & $\begin{array}{l}\text { February } \\
\pm \text { S.E }\end{array}$ & $\begin{array}{l}\text { March } \\
\pm \text { S.E }\end{array}$ & $\begin{array}{l}\text { Mean \% survival } \\
\pm \text { S.E }\end{array}$ \\
\hline Tamarind seeds & $93.75 \pm 1.30$ & $92.80 \pm 1.60$ & $89.31 \pm 2.30$ & $80.37 \pm 2.40$ & $89.06 \pm 1.60^{\mathrm{a}}$ \\
\hline Maize & $65.75 \pm 2.20$ & $64.45 \pm 3.40$ & $26.76 \pm 3.80$ & $5.63 \pm 3.30$ & $40.65 \pm 6.80^{\mathrm{b}}$ \\
\hline Sorghum & $57.5 \pm 3.20$ & $58.11 \pm 4.80$ & $33.45 \pm 6.80$ & $2.5 \pm 2.50$ & $37.89 \pm 6.20^{\mathrm{bc}}$ \\
\hline Mean \% survival & $72.33 \pm 11.00^{\mathrm{a}}$ & $71.79 \pm 10.70^{\mathrm{a}}$ & $49.84 \pm 19.80^{\mathrm{b}}$ & $26.10 \pm 25.50^{\mathrm{c}}$ & $*$ LSD $5.70 / 4.94$ \\
\hline
\end{tabular}

* LSD (5\%) Months-5.7; Substrates- 4.94

LSD is the Least Significant Difference; S.E is Standard Error

Means bearing the same letter (superscript) in the same row/column are not significantly different at the $5 \%$ 
probability level

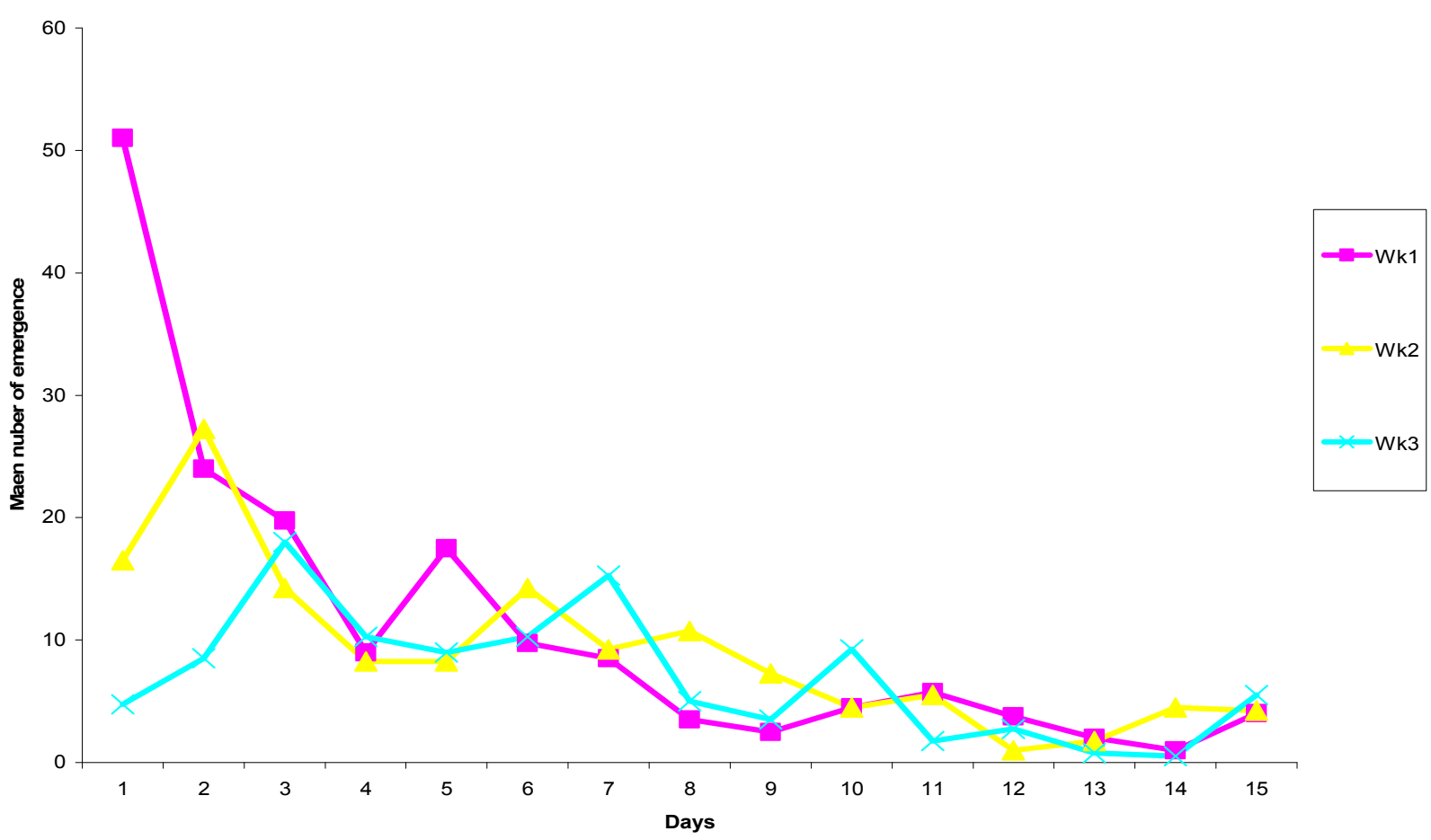

Figure 1. Mean number of adults that emerged per day over a period of fifteen days

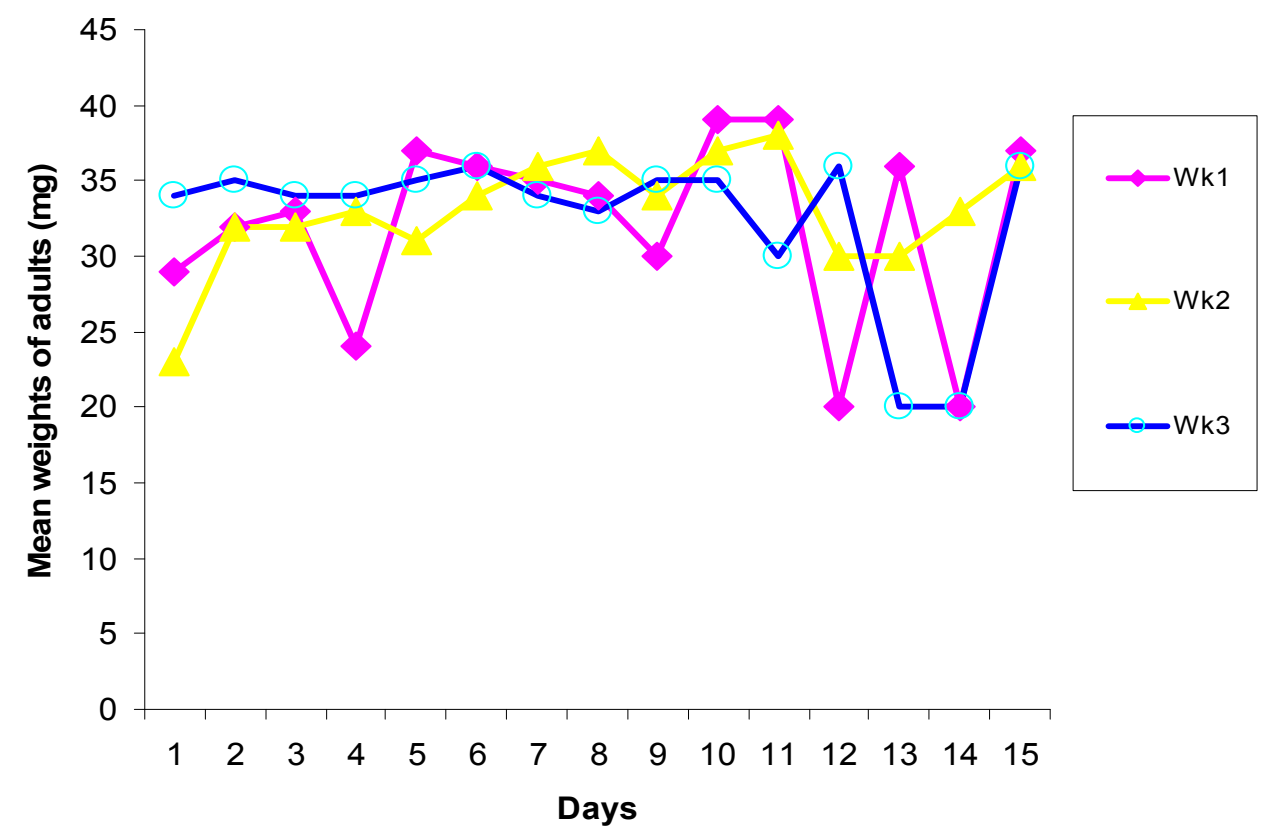

Figure 2. Mean weights of adult insects recorded daily over a period of fifteen days 